\title{
The effect of irrigation uniformity on irrigation water requirements
}

\author{
GW Ascough ${ }^{1,2 *}$ and GA Kiker ${ }^{2}$ \\ ${ }^{1}$ Agricultural Research Council- Institute for Agricultural Engineering, PO Box 2252, Dennesig 7601, South Africa \\ ${ }^{2}$ School of Bioresources Engineering and Environmental Hydrology, University of Natal, Private Bag X01, Scottsville 3209, South Africa
}

\begin{abstract}
Irrigated agriculture is the largest user of water in South Africa. Due to the limited amount of water resources, the efficient and equitable use of water is of paramount importance. This can only be achieved through effective design, maintenance and management of irrigation systems. The uniformity with which an irrigation system applies water has an affect on the efficiency of the system. The uniformity of an irrigation system needs to be high to ensure that the majority of the crop receives an adequate amount of water. This is needed for fields to produce high yields and to have minimal nutrient loss due to deep percolation. The uniformity of application also plays an important role in determining water allocations and the gross amount of irrigation water to apply. The concept of uniformity and calculation thereof are presented in this paper.

Results of research of the application uniformity of different irrigation systems in the sugar industry in five sugar-growing regions in South Africa will be discussed in this paper. From this study the average low-quarter distribution uniformity (DU $\mathrm{la}_{\mathrm{lq}}$ ) of centre pivot, dragline, micro-irrigation, floppy and semi-permanent sprinkler systems was $81.4 \%, 60.9 \%, 72.7 \%, 67.4 \%$, and $56.9 \%$ respectively. The percentage of systems that had an excellent field condition $\mathrm{DU}_{\mathrm{lq}}$ was $100 \%$ for centre pivot, $15.4 \%$ for dragline, $30 \%$ for micro-irrigation, $0 \%$ for floppy, and $14.3 \%$ for semi-permanent sprinkler systems. Only three floppy irrigation systems were evaluated during this study, therefore the result for the percentage of systems with an excellent $\mathrm{DU}_{\mathrm{lq}}$ may not be representative of these systems in general. Irrigation systems that were well maintained and correctly operated generally had a high and acceptable $\mathrm{DU}_{\mathrm{lq}}$. The average application efficiencies (AE) were $83.6 \%$ for centre pivot, $73.5 \%$ for dragline, $76.7 \%$ for floppy, and $78.9 \%$ for semi-permanent sprinkler systems.
\end{abstract}

\section{Introduction}

Irrigated agriculture is the largest user of water resources in South Africa, using 53\% of the total annual amount used (WRC, 1999). The National Water Act (1998) requires the economical and sustainable use of water. Thus, water resources have to be utilised in such a manner as to protect and conserve the available water reserves. In irrigated agriculture this will have to be obtained through the effective management of water consumption. Therefore, irrigation systems will have to apply water in the most efficient way possible to prevent unnecessary losses and water wastage.

In order to achieve this, the uniformity with which the irrigation system applies water will have to be high. The distribution uniformity of a system has an effect on the system's application efficiency and on the crop yield (Letey et al., 1984; Solomon, 1984; Letey, 1985; Solomon, 1990). Irrigation systems with poor distribution uniformity experience reduced yields due to water stress and/or water logging (Solomon, 1983; cited by Clemmens and Solomon, 1997). Poor distribution uniformity also has increased financial and environmental costs. Nutrients can be leached out of the soil due to excess water being applied to overcome poor irrigation uniformity. This will increase fertiliser costs and pumping costs, and may have environmental impacts if the excess runoff and deep percolation are contaminated with nutrients (Solomon, 1990).

The distribution uniformity of an irrigation system depends both on the system characteristics and on managerial decisions (Pereira, 1999). The distribution uniformity of different types of

\footnotetext{
* To whom all correspondence should be addressed.

前 021809 3500; fax: 021809 3501; e-mail: grega@infruit.agric.za Received 30 November 2001; accepted in revised form 12 March 2002.
}

irrigation will be influenced by different factors that are characteristic of the particular system. Surface irrigation is influenced primarily by soil intake characteristics. Overhead irrigation is influenced by the condition of sprinkler packages and the pressure variation within the system. It is also influenced by the strength and direction of the wind (Burt et al., 1997). These factors of an irrigation system need to be correctly managed to ensure that the distribution uniformity is at an acceptable level. This will ensure the optimal use of water resources.

To ensure that the farmer receives an adequate water allocation for his irrigation system, the distribution uniformity needs to be included in the gross irrigation water requirement calculation. This factor can be used in conjunction with the factor representing spray and conveyance losses to estimate the gross irrigation water requirement from crop water requirement (Burt et al., 1997). The distribution uniformity that is included in these design calculations needs to be determined. An acceptable lower limit to the distribution uniformity must be one that is reasonable and obtainable (Pitts et al., 1996). Farmers that follow best management practices should be able to reach these levels. This will ensure an adequate water allocation and the prudent use of water.

The Agricultural Research Council - Institute for Agricultural Engineering (ARC-ILI) conducted a study, on behalf of the South African Sugar Association (SASA), to quantify the distribution uniformity and application efficiency of irrigation systems used in the sugar industry. In total 38 systems were evaluated, including the following system types; dragline, semi-permanent sprinklers, centre pivot, drip, micro-spray, and floppy sprinklers. The study was conducted in five major sugar irrigation areas in KwaZulu-Natal and Mpumalanga provinces. The results of this study and a discussion on the importance of irrigation uniformity will be the focus of this paper. 


\section{Uniformity coefficients}

There are several coefficients of uniformity that are used to describe the uniformity of irrigation systems.

\section{Coefficient of uniformity}

One of the first criteria defined to express uniformity was the coefficient of uniformity (CU) as defined by Christiansen (1942). Christiansen's CU is the most widely used and accepted criterium used to define uniformity (Zoldoske et al., 1994). This coefficient is derived from catch-can data assuming that the catch-cans represent the same area. It is a measure of the absolute difference from the mean divided by the mean. The CU can be expressed by (ASAE, 1993a):

$$
\mathrm{CU}=100\left(1-\frac{\sum_{\mathrm{n}}\left|\mathrm{D}_{\mathrm{s}}-\overline{\mathrm{D}}\right|}{\sum_{\mathrm{n}} \mathrm{D}_{\mathrm{s}}}\right)
$$

where:

$\mathrm{D}_{\mathrm{s}}$ is the catch-can depth of application,

$\overline{\mathrm{D}}$ is the mean catch-can depth, and

$\mathrm{n}$ is the number of catch cans.

Heermann and Hein (1968) modified this expression for use with centre pivot catch-can data. Equation 1 was modified to include a term representing the distance from the centre to the catch-can, $S_{\text {s. }}$. The modified Heermann-Hein $\mathrm{CU}_{\mathrm{HH}}$ equation is given by (ASAE, 1993a):

$$
\mathrm{CU}_{\mathrm{HH}}=100\left(1-\sum_{\mathrm{n}} \mathrm{S}_{\mathrm{s}}\left|\mathrm{D}_{\mathrm{s}}-\frac{\sum_{\mathrm{n}} \mathrm{D}_{\mathrm{s}} \mathrm{S}_{\mathrm{s}}}{\sum_{\mathrm{n}} \mathrm{S}_{\mathrm{s}}}\right| / \sum_{\mathrm{n}} \mathrm{D}_{\mathrm{s}} \mathrm{S}_{\mathrm{s}}\right)
$$

There are three features of $\mathrm{CU}$, and $\mathrm{CU}_{\mathrm{HH}}$, that should be considered when interpreting the uniformity values obtained (Zoldoske et al., 1994):

- Firstly, the absolute difference between the measured and mean depth of application results in over- and under-irrigation is being treated equally. Thus the deviations are represented by magnitude only and not by whether they represent a deficit or excess of irrigation water, one of which may be more critical than the other for the crop.

- Secondly, the penalty assigned to each deviation is linearly proportional to the magnitude of the deviation.

- Thirdly, CU is an average measure and as such compares the average absolute deviation to the mean application. Thus CU indicates on average how uniform the application depths are and does not give an indication of how bad a particular area may be, or how large the area may be.

\section{Distribution uniformity}

Distribution uniformity (DU) is usually defined as a ratio of the smallest accumulated depths in the distribution to the average depths of the whole distribution. The largest depths could also be used to express DU, but since the low values in irrigation are more critical, the smallest values are used (Burt et al., 1997). The average of the smallest depths in the field over the portion of the field, in which they occur, is given the notation $\mathrm{d}_{\text {lowest }}$. This term is used in the numerator of the DU calculation. The values of DU will thus depend on the choice of the fraction of the total area for which the smallest values will be taken. This area does not have to be contiguous. A commonly used fraction is the lower quarter, which has been used by the United States Department of Agriculture (USDA) since the 1940s. This definition has proven useful in irrigated agriculture (ASCE, 1978) and leads to the definition of the average low-quarter depth, $\mathrm{d}_{\mathrm{lq}}$. Thus, the average accumulated depth in the quarter of the field receiving the smallest depths is given by (Burt et al., 1997):

\section{$d_{1}=$ volume accumulated in $25 \%$ of total area of all elements with smallest depths total area of $25 \%$ of the total area of elements}

From this the low-quarter distribution uniformity, $\mathrm{DU}_{\mathrm{lq}}$, can be defined as:

$$
\begin{aligned}
& \mathrm{DU}_{\mathrm{lq}}=\frac{\mathrm{d}_{\mathrm{lq}}}{\mathrm{d}_{\mathrm{avg}}} \\
& \mathrm{DU}_{\mathrm{lq}}=\frac{\text { average low quarter depth }}{\text { average depth of water accumulated in all elements }}
\end{aligned}
$$

where:

$\mathrm{d}_{\mathrm{avg}}$ is the total volume accumulated in all elements $\left[\mathrm{m}^{3}\right]$ divided by the total area of all the elements $\left[\mathrm{m}^{2}\right]$.

The area of an element depends on the crop being irrigated. In row crops, such as wheat, the elemental area will be the entire field as there is a crop at every point in the field. In orchards, the elemental area will be the rooting area of each tree. These definitions allow the elements to be of different sizes by using area weighting (Burt et al., 1997).

\section{Statistical uniformity}

The uniformity of an irrigation system can be expressed using the coefficient of variation $(\mathrm{CV})$. The statistical uniformity $(\mathrm{SU})$ can be expressed by (ASAE, 1993b):

$$
\mathrm{SU}=100(1-\mathrm{CV})
$$

The SU is usually used to represent the uniformity of microirrigation systems, such as drip and micro-spray systems. The CU and $\mathrm{DU}_{\mathrm{lq}}$ can also be expressed in terms of $\mathrm{CV}$ if a normal distribution is assumed for the distribution of water. These are the statistically derived estimates for the uniformity. The statistical estimates for the coefficient of uniformity (SCU) and the lowquarter distribution uniformity $\left(\mathrm{SDU}_{\mathrm{lq}}\right)$ are given by (Burt et al., 1997):

$$
\begin{aligned}
& \mathrm{SCU}=100(1-0.798 \mathrm{CV}) \% \\
& \mathrm{SDU}_{\mathrm{lq}}=1-1.27 \mathrm{CV}
\end{aligned}
$$

In Eq. (7) and Eq. (8) the CV is a ratio and not a percentage.

\section{Emission uniformity}

The emission uniformity is used to characterise the uniformity of micro-irrigation systems and is given by Karmeli and Keller (1974; cited by Clemmens and Solomon, 1997) as:

$$
\mathrm{EU}=\left(1-1.27 \frac{\mathrm{CV}_{\mathrm{M}}}{\sqrt{\mathrm{n}}}\right)\left(\frac{\mathrm{Q}_{\mathrm{lq}}}{\mathrm{Q}_{\mathrm{avg}}}\right) \times 100 \%
$$


where:

$\mathrm{CV}_{\mathrm{M}}$ is the manufacturers' coefficient of variation for emitters, $\mathrm{n}$ is the number of emitters per plant,

$\mathrm{Q}_{\mathrm{lq}}$ is the average low-quarter emitter discharge [1/h], and $\mathrm{Q}_{\mathrm{avg}}$ is the overall average of emitter discharges $[1 / \mathrm{h}]$ assuming the same pressure-discharge relationship for all emitters.

In Eq. (9) the first term on the right-hand side accounts for emitter variation and the second accounts for system pressure variation.

\section{Importance of irrigation uniformity}

The uniformity of each type of irrigation system is influenced by different factors. The factors that affect the uniformity of surface, sprinkler and micro-irrigation systems are given by (Pereira, 1999):

- $\quad$ Surface irrigation: $\mathrm{DU}=f(\mathrm{qin}, \mathrm{L}, \mathrm{n}, \mathrm{So}, \mathrm{Ic}, \mathrm{Fa}, \mathrm{tco})$

where:

qin is the inflow rate,

$\mathrm{L}$ is the length of the furrow or basin,

$\mathrm{n}$ is the roughness coefficient of the furrow,

So is the longitudinal slope of field,

Ic is the intake characteristics of the soil,

$\mathrm{Fa}$ is the cross sectional shape of furrow or basin, and tco is the cut-off time.

- $\quad$ Sprinkler irrigation: $\mathrm{DU}=f(\mathrm{P}, \mathrm{DP}, \mathrm{S}, \mathrm{dn}, \mathrm{WDP}, \mathrm{WS})$ where:

$\mathrm{P}$ is the pressure at the sprinkler,

$\mathrm{DP}$ is the variation in pressure in the operating set,

$\mathrm{S}$ is the sprinkler spacing,

$\mathrm{dn}$ is the nozzle diameter influencing discharge and wetted diameter,

WDP is the water distribution pattern, and

WS is the wind speed and direction.

- Micro-irrigation irrigation: $\mathrm{DU}=f(\mathrm{P}, \mathrm{DP}, \mathrm{x}, \mathrm{Ec}, \mathrm{Cv}, \mathrm{FI})$

where:

$\mathrm{P}$ is the pressure at the emitter,

DP is the variation in pressure along the system,

$\mathrm{x}$ is the characteristic discharge exponent of the emitter,

Ec is the emitter characteristics related to variation in discharge,

$\mathrm{Cv}$ is the manufacturing variation in emitter discharge, and

FI is the filtering capabilities of the system.

Therefore, it is important that these factors are considered when an irrigation system is designed and managed in order to ensure an application of water that is as uniform as possible. Regular evaluation of irrigations should take place so that the systems are correctly maintained and are performing according to design (Pereira, 1999).

The design and management of an irrigation system are not the only factors that influence uniformity. Perrens (1984) and $\mathrm{Li}$ (1998) found that the uniformity of soil moisture from a non-uniform application of irrigation water at the soil surface improves over time. This is due to lateral flow within the soil matrix and a redistribution of soil moisture.

The uniformity of application can be incorporated into the calculation of gross irrigation water requirements using the following principles. Potential application efficiency (PAE) is based on the concept that the irrigation event could be terminated when the target depth would just be met by the average of the lowest values in the irrigation infiltration distribution. In this way deep percolation losses would be kept to a minimum, due only to the non-uniformity of application, and the application efficiency would be at a maximum with minimal under-irrigation (Burt et al., 1997).

As with DU, PAE cannot be quantified until the lowest values in the distribution have been characterised over a specified fraction of the field area. Here again the norm is to use the lower quarter and hence the definition for $\mathrm{PAE}_{\mathrm{lq}}$ follows (Burt et al., 1997):

$\mathrm{PAE}_{\mathrm{lq}}=\frac{\text { average depth of irrigation water contributing to target }}{\text { average depth of irrigation water applied such that } d_{l q}=\text { target }} \times 100 \%$

Thus, $\mathrm{PAE}_{\mathrm{lq}}$ can be used to estimate the gross amount of water to apply. The denominators of $\mathrm{DU}_{\mathrm{lq}}$ and $\mathrm{PAE}_{\mathrm{lq}}$ differ by the amount of surface losses, such as runoff and evaporation, and therefore $\mathrm{PAE}_{\mathrm{lq}}$ can be accurately estimated from (Burt et al., 1997):

$$
\mathrm{PAE}_{\mathrm{lq}} \approx \mathrm{DU}_{\mathrm{lq}} \times(100-\% \text { surface losses })
$$

where surface losses include evaporation during an irrigation event, spray drift and surface runoff.

From the above, the gross amount of irrigation water required for an irrigation event can be estimated as (Burt et al., 1997):

$$
\text { Gross average depth to apply }=\text { Target depth } \times \frac{100}{\mathrm{PAE}_{\mathrm{lq}}}
$$

Equation (12) can be used to calculate the gross amount of irrigation water required for the scenario where there is minimal underirrigation. For scenarios where more of the field receives less than the required amount, the gross amount of water to apply can be calculated using a theoretical water distribution; e.g. a normal distribution for sprinkler irrigation (De Juan et al., 1996).

To apply the above method of calculating the gross amount of irrigation water to apply, an acceptable estimate of $\mathrm{DU}_{\mathrm{lq}}$ is needed. An acceptable and reasonable lower limit for $\mathrm{DU}_{\mathrm{lg}}$ is one that is attainable and economically viable. Pitts et al. (1996) conducted a study of the distribution uniformity of 385 irrigation systems and developed some acceptable standards for $\mathrm{DU}_{\mathrm{lq}}$ based on best management practices. These standards as well as a summary of the results from this study are given in Table 1. Many of the evaluated systems had a $\mathrm{DU}_{\mathrm{lq}}$ that was below the standard $\mathrm{DU}_{\mathrm{lq}}$. Those irrigators that applied best management practices were able to meet

\begin{tabular}{|c|c|c|c|}
\hline \multicolumn{4}{|c|}{$\begin{array}{c}\text { TABLE } 1 \\
\text { Summary of } \mathrm{DU}_{\mathrm{lq}} \text { evaluations and standards for } \mathrm{DU}_{\mathrm{lq}} \\
\text { (after Pitts et al., 1996) }\end{array}$} \\
\hline Irrigation type & $\begin{array}{l}\text { Number of } \\
\text { evaluations }\end{array}$ & $\underset{[\%]}{\text { Average }} \mathrm{DU}_{\mathrm{lq}}$ & $\begin{array}{c}\text { Standard } \mathrm{DU}_{\mathrm{Ic}} \\
{[\%]}\end{array}$ \\
\hline Agricultural sprinkler & 159 & 65 & 75 \\
\hline Micro-irrigation & 174 & 70 & 85 \\
\hline Furrow & 15 & 70 & 65 \\
\hline Turf & 37 & 49 & 75 \\
\hline
\end{tabular}
or exceed the standard $\mathrm{DU}_{\mathrm{lq}}$ (Pitts et al., 1996). 


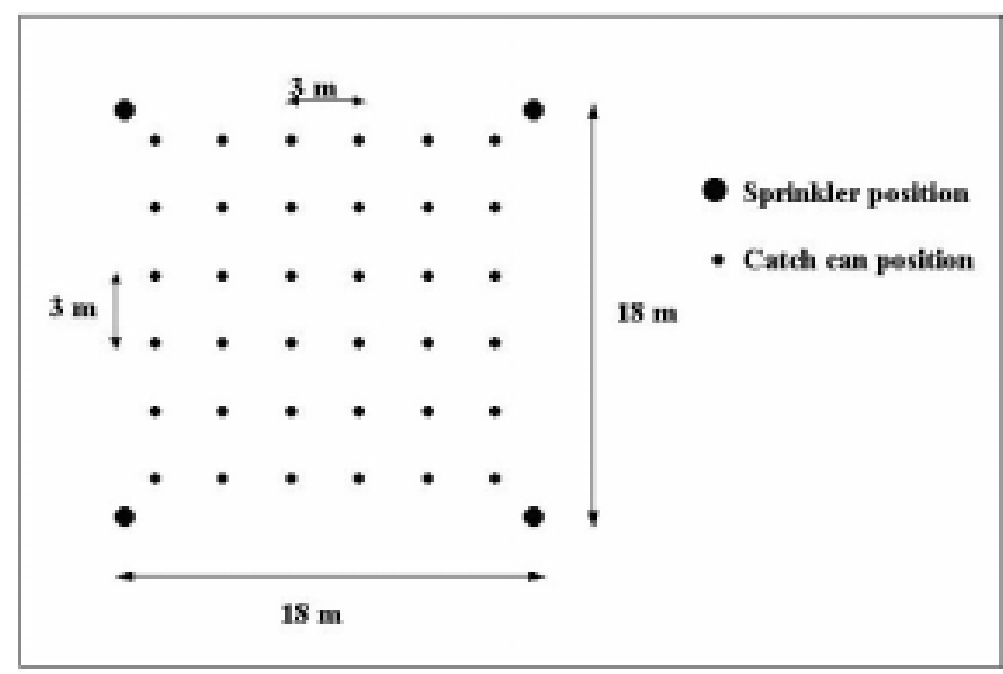

Figure 1

Sprinkler catch-can pattern

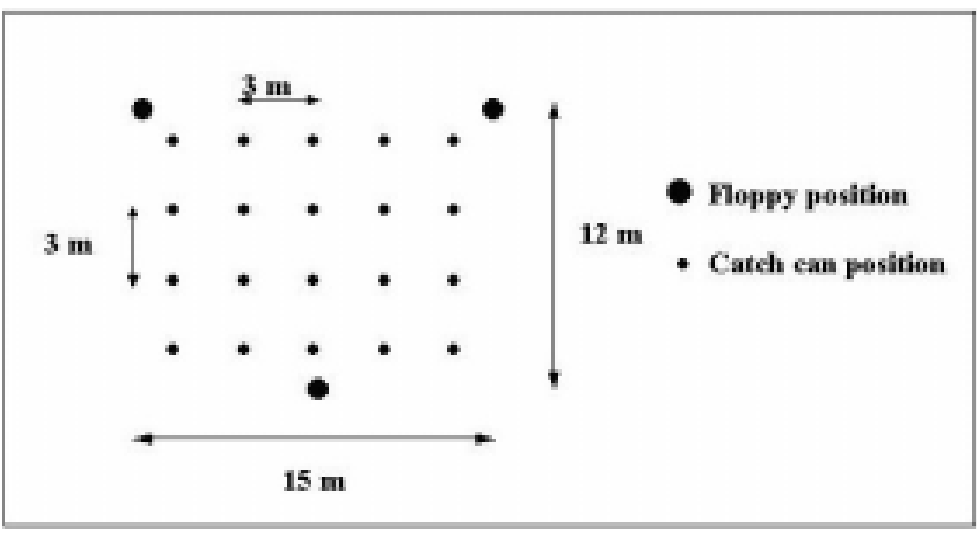

Figure 2

Floppy catch-can pattern

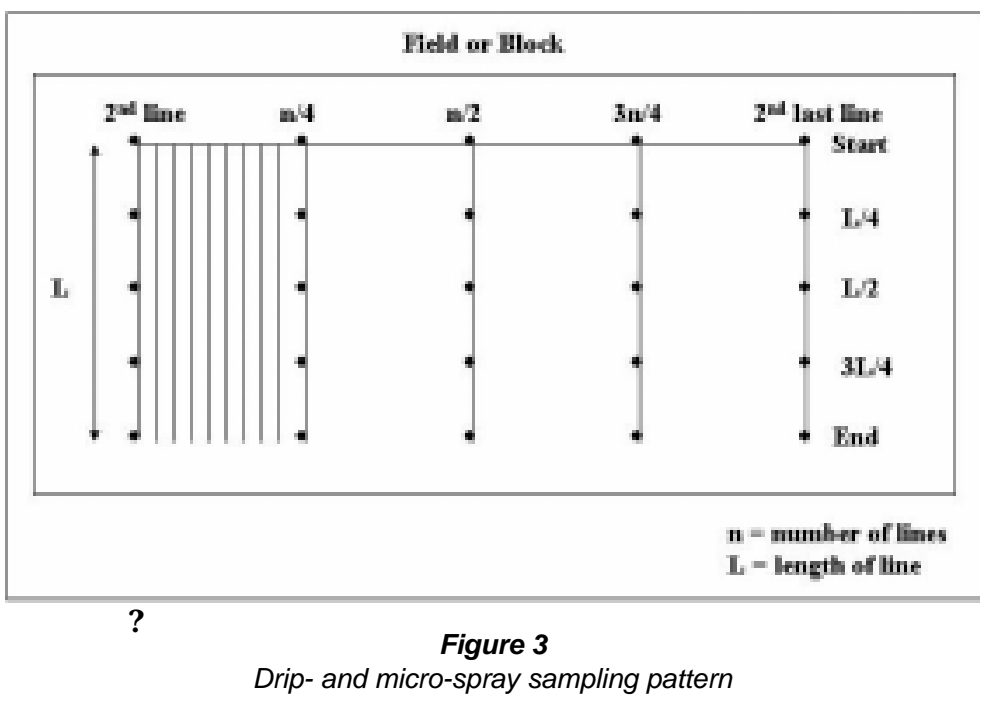

\section{Methodology}

The evaluation method for determining the distribution of water under the various irrigation systems was based on the following American Society of Agricultural Engineers (ASAE) Standards:

- Centre pivot - ASAE S436 (ASAE, 1993a),

- Micro-irrigation systems-ASAEEP458(ASAE, 1993b),

- Overhead sprinklers - ASAE S398.1 (ASAE, 1993c).

To evaluate the application efficiency of the irrigation systems, excluding drip- and micro-irrigation systems, the following definition of application efficiency (AE) was used:

$$
\mathrm{AE}=\frac{\text { average depth on soil surface }}{\text { average depth of water leaving the emitter }}
$$

For centre pivots, the average depth leaving the emitter was assumed to be the depth setting as stated on the centre pivot control computer. For the other irrigation systems a volumetric flow measurement taken against time and the sprinkler area was used to calculate an average depth.

The number of catch-cans placed in the test block depended on the system being tested and the spacing of the emitters. For dragline and semi-permanent systems 36 catch cans were placed between four sprinkler positions. A spacing of $3 \mathrm{~m}$ was used between catch cans. This configuration can be seen in Fig. 1. The sampling used for floppy sprinklers is shown in Fig. 2. The typical spacing for these sprinklers is $15 \mathrm{mx} 12 \mathrm{~m}$. For these systems, 20 catch cans were used to determine the uniformity. For these tests a standard rain gauge was used as the collection device. The depth was recorded from the rain gauge. Figure 3 shows the sampling pattern for micro-irrigation systems. The water delivery was measured at 25 points in a block. The lines in a block that were selected for the evaluation were the second line, the lines at a quarter, half and three-quarter distances, and the second to last line of the block. On each line the delivery of five emitters was measured. These were situated at the start of the line, at a quarter, half and three-quarter length and at the end of the line. The delivery of the emitters was measured using a container placed under the emitter and a graduated measuring cylinder with $1 \mathrm{~mm}$ graduations. A single line of catch cans along the radius of the centre pivot was used to characterise the distribution of water applied. Depending on the length of the pivot, a catch-can spacing of $5 \mathrm{~m}$ or $7 \mathrm{~m}$ was used. The total number of catch cans used varied between 63 and 75 .

The data collected were analysed for uniformity using Eqs. (1)

A uniform irrigation event does not mean that the irrigation will be efficient. If there is an over-application of a uniform irrigation that produces excess deep percolation, then the irrigation application will not be efficient (Pitts et al., 1996; Rogers et al., 1997). to (9). For the study, 13 dragline, 7 semi-permanent sprinkler, 5 centre pivot, 8 drip, 2 micro-spray, and 3 floppy systems were evaluated. 


\begin{tabular}{|l|c|c|c|c|c|}
\hline \multicolumn{6}{|c|}{ TABLE 2 } \\
\hline Summary of uniformity parameters by irrigation type \\
\hline & \multicolumn{5}{|c|}{ Irrigation system type } \\
\cline { 2 - 6 } & $\begin{array}{c}\text { Centre } \\
\text { pivot }\end{array}$ & Dragline & $\begin{array}{c}\text { Drip and } \\
\text { micro-spray }\end{array}$ & Floppy & $\begin{array}{c}\text { Semi- } \\
\text { permanent } \\
\text { sprinkler }\end{array}$ \\
\hline $\begin{array}{l}\text { CU [\%] (EU [\%]) } \\
\text { DU [\%] }\end{array}$ & 88.0 & 74.0 & $81.6(76.3)$ & 74.5 & 70.8 \\
Standard DU $[\%]$ & 81.4 & 60.9 & 72.7 & 67.4 & 56.9 \\
(from Table 3.1) & 75 & 75 & 85 & 75 & 75 \\
$\begin{array}{l}\text { Systems with excellent } \\
\text { field condition DU }\end{array}$ & 100 & 15.4 & 30 & 0 & 14.3 \\
\hline
\end{tabular}

\begin{tabular}{|l|c|c|c|c|c|}
\hline \multicolumn{6}{|c|}{$\begin{array}{c}\text { TABLE 3 } \\
\text { Summary of application efficiency by type of irrigation system }\end{array}$} \\
\hline & \multicolumn{5}{|c|}{ Type of irrigation system } \\
\cline { 2 - 6 } & $\begin{array}{c}\text { All } \\
\text { systems }\end{array}$ & $\begin{array}{c}\text { Centre } \\
\text { pivot }\end{array}$ & Dragline & Floppy & $\begin{array}{c}\text { Semi- } \\
\text { permanent } \\
\text { sprinkler }\end{array}$ \\
\hline Average AE [\%] & 77.0 & 83.6 & 73.5 & 76.7 & 78.9 \\
Minimum AE [\%] & 58.9 & 76.3 & 58.9 & 63.5 & 64.6 \\
Maximum AE [\%] & 93.8 & 93.8 & 89.3 & 85.4 & 91.1 \\
SABI AE norms [\%] & - & 85 & 75 & 85 & 75 \\
(SABI, 2000) & & & & & \\
\hline
\end{tabular}

\section{Results and discussion}

The results for the coefficient of uniformity $(\mathrm{CU})$ and low-quarter distribution uniformity are shown in Table 2 and Fig. 4 to Fig. 8. The majority of the systems had a DU $\mathrm{Iq}_{\mathrm{lq}}$ lower than the standard $\mathrm{DU}_{\mathrm{lg}}$ suggested by Pitts et al. (1996). All the centre pivots evaluated had an excellent $\mathrm{DU}_{\mathrm{q}}$ and none of the floppy systems tested exceeded the standard $\mathrm{DU}_{\mathrm{lq}}$. During this study only three floppy irrigation systems were evaluated, therefore the result for the percentage of systems with an excellent $\mathrm{DU}_{\mathrm{lq}}$ may not be representative of these systems in general. A possible explanation for the substandard performance of the overhead irrigation systems could be the system pressure and wind speed. During the evaluations the wind speed varied from $1 \mathrm{~m} / \mathrm{s}$ to $6 \mathrm{~m} / \mathrm{s}$ and the coefficient of variation of nozzle system pressure ranged from $1.36 \%$ to $37.5 \%$. Of the 20 dragline and semi-permanent sprinkler systems tested, only 6 of them were operating within an acceptable pressure range. Many of these systems were operating at too low a nozzle pressure.

A summary of the application efficiency obtained for the overhead irrigation systems is shown in Table 2. The application efficiency of each system evaluated can be seen in Figs. 4 and 5 and Figs. 7 and 8. From the figures it can seen that the systems that exhibited high uniformities generally had high application efficiencies. It can also be seen that some of the systems that had a poorer $\mathrm{DU}_{\mathrm{lq}}$ also had high application efficiency. An example of this is System 33 in Fig. 8, the DU, was $56 \%$ and the AE was $89.4 \%$. This is due to the definition of $\mathrm{AE}$ where averages are used. Here the AE was high because the average depth emitted from the sprinkler compared to the average depth recorded on the ground was similar. However, the $\mathrm{DU}_{\mathrm{lq}}$ shows that the low quarter of the area received only $56 \%$ of the average. This means that underirrigation has occurred in the test area. This may have implications for crop yield and excess deep percolation. The average AE for the irrigation system types is close to the norms suggested by the South African Irrigation Institute (SABI, 2000). These norms represent the average spray and evaporation losses of the irrigation system.

The variation in $\mathrm{CU}$, EU and $\mathrm{DU}_{\mathrm{lq}}$ values determined can be seen in Figs. 4 and 5. The CU ranged from $17.4 \%$ to $95.2 \%$, the EU ranged from $25.4 \%$ to $92.5 \%$, and the $\mathrm{DU}_{\mathrm{lq}}$ ranged from $0 \%$ to $91.9 \%$. The drip- and micro-spray systems had some of the best application uniformities. The semi-permanent sprinkler and dragline systems had the most variability in the application uniformities calculated. The irrigation systems that were well maintained and correctly operated were the systems that had high uniformity.

It should be emphasised that the results obtained during the study were under the particular field and climatic conditions at the time of the test. Since wind has a large impact on the distribution of irrigation water, a test conducted in lesser wind conditions may have shown better results. Also, the tests were conducted on irrigation systems that had been in normal operation and not on new systems. The results should therefore be viewed in the light that the tests were conducted in conditions that may not have been optimal.

\section{Conclusions}

In order to conserve water resources, close attention has to be paid to the performance of irrigation systems. Irrigation systems should be evaluated on a regular basis to ensure that the systems are well 


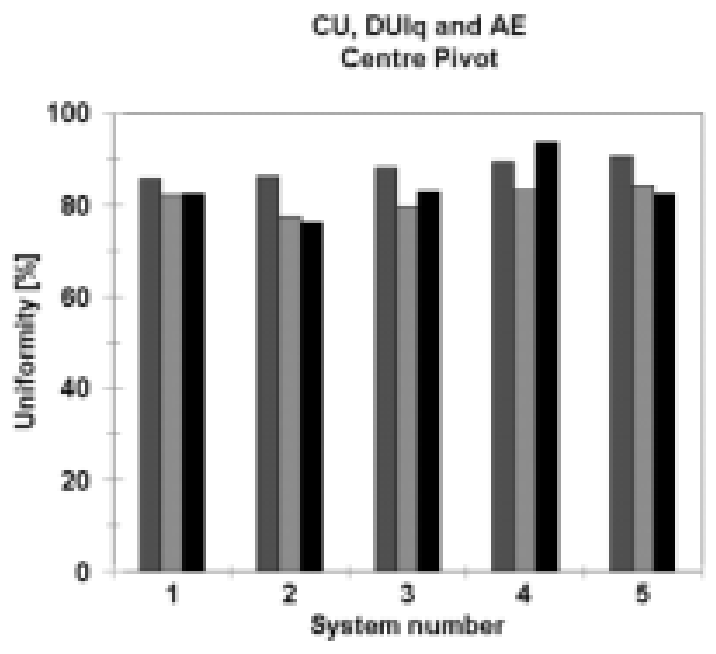

Figure 4

$C U, D U_{\text {lq }}$ and $A E$ of centre pivot systems

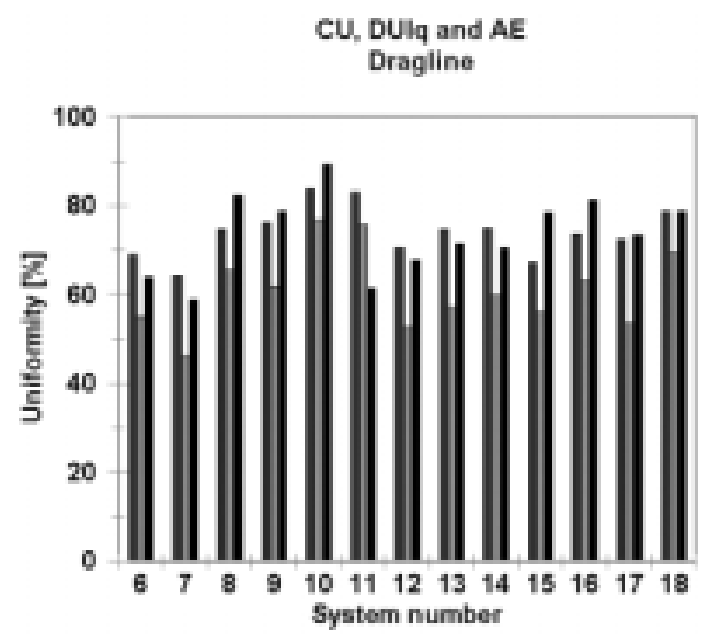

Figure 5

$C U, D U_{l q}$ and $A E$ of dragline systems

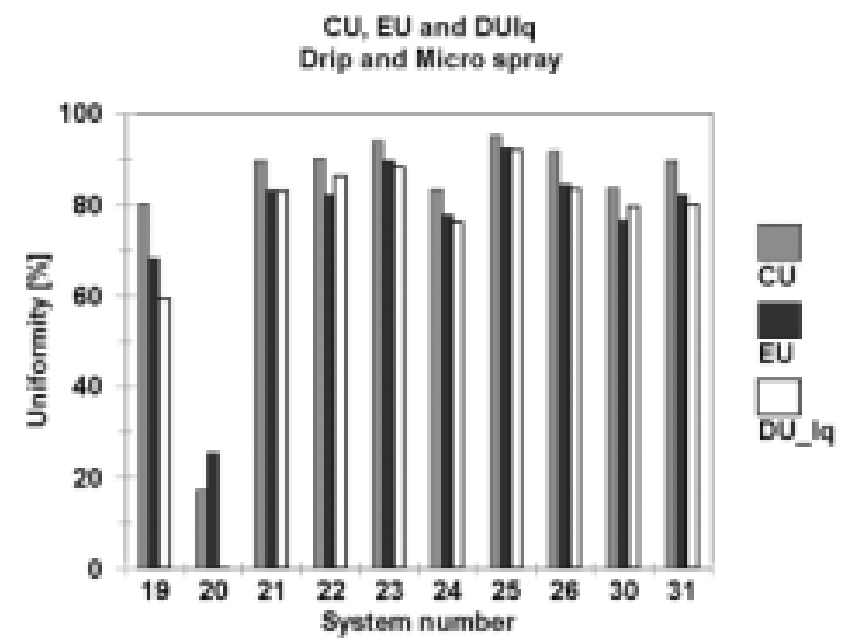

Figure 6

$C U, E U$ and $D U_{1 q}$ of micro-irrigation systems

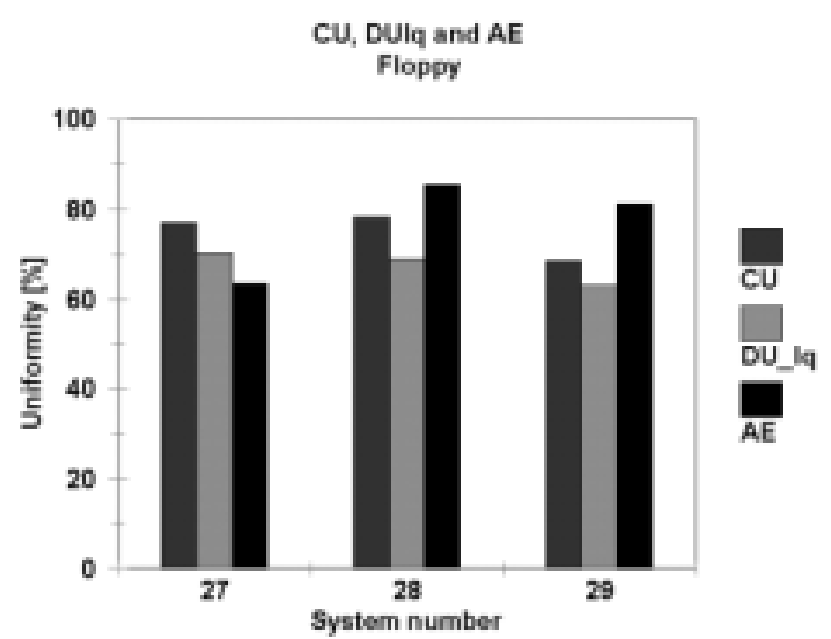

Figure 7

$C U, D U_{1 q}$ and $A E$ of floppy systems

\section{CU, DUlq and AE}

Semi-permanent sprinkler

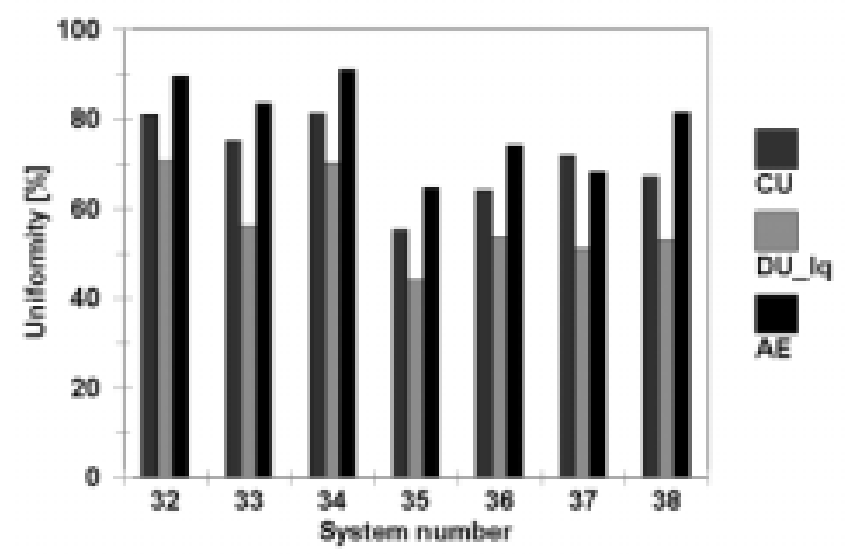

Figure 8

$C U, D U_{l q}$ and $A E$ of semi-permanent sprinkler systems

maintained and are performing according to design. The irrigation system must also be managed correctly and effectively. The distribution uniformity of a system must be as uniform as possible to ensure higher yields and the efficient application of water. It should also be included in the calculation of water allocations and the determination of gross irrigation water requirement.

The results of the study conducted show that more attention needs to be paid to the distribution uniformity of an irrigation system. Toimprove the distribution uniformity of irrigation systems they need to be properly maintained and operated. Especially, overhead irrigation systems need to be operated at the correct pressure and in low wind conditions. The results also show that a well-maintained and correctly operated system can achieve or exceed a distribution uniformity that is considered reasonable and acceptable.

An irrigation system can have high application efficiency and have poor DU. Even though the water is being used efficiently, with minimal spray and/or evaporation loss, large areas of the crop may not be receiving an adequate amount of water. This could lead to crop stress and reduced yields. Therefore the importance of the uniformity should not be ignored. It is only possible to achieve high 
application efficiencies with minimal under-irrigation if the DUs are high.

\section{Acknowledgements}

The South African Sugar Association and the Agricultural Research Council- Institute for Agricultural Engineering are gratefully acknowledged for the use of the results from the study conducted.

\section{References}

ASAESTANDARDS (1993a) S436 (40 $0^{\text {th }}$ edn.) Test Procedure for Determining the Uniformity of Water Distribution of Center Pivot, Corner Pivot, and moving Lateral Irrigation Machines Equipped with Spray or Sprinkler Nozzles. ASAE, St. Joseph, Mich., USA.

ASAE STANDARDS (1993b) EP458 (40 $0^{\text {th }}$ edn.) Field Evaluations of Microirrigation Systems. ASAE, St. Joseph, Mich., USA.

ASAE STANDARDS (1993c) S398.1 (40 th edn.) Procedure for Sprinkler Testing and Performance Reporting. ASAE, St. Joseph, Mich., USA.

ASCE (1978) Describing irrigation efficiency and uniformity. J. Irrig. Drain. Div. 104 (1) 35-41.

BURT CM, CLEMMENS AJ, STRELKOFF TS, SOLOMON KH, BLIESNER RD, HARDY LA, HOWELL TA and EISENHAUER DE (1997) Irrigation performance measures: Efficiency and uniformity. $J$. Irrig. Drain. Eng. 123 (6) 423-442.

CHRISTIANSEN J E (1942) Irrigation by Sprinkling. California Agricultural Experiment Station, Bull. 670, University of California, Berkley, USA.

CLEMMENS AJ and SOLOMON KH(1997) Estimation of global irrigation distribution uniformity. J. Irrig. Drain. Eng. 123 (6) 454-461.

DE JAUN JA, TARJUELO JM, VALIENTE M and GARCIA P (1996) Model for optimal cropping patterns within the farm based on crop water production functions and irrigation uniformity: I. Development of decision model. Agric. Water Manage. 31(1-2) 115-143.

HEERMAN DF and HEIN PR (1968) Performance characteristics of self-propelled centre-pivot sprinkler irrigation systems. Trans. ASAE. 11 (1) $11-15$

KARMELI D and KELLER J (1974) Trickle Irrigation Design. Rain Bird Sprinkler Manufacturing Corporation, Glendora, USA.
LETEY J (1985) Irrigation uniformity as related to optimum crop productionAdditional research is needed. Irrig. Sci. 6 253-263.

LETEY J, VAUX HJ and FEINERMAN E (1984) Optimum crop water applications as affected by uniformity of water infiltration. Agron.J. 76 435-441.

LI J (1998) Modeling crop yield as affected by uniformity of sprinkler irrigation system. Agric. Water Manage. 38 (2) 135-146.

NATIONAL WATER ACT (1998) RSA Government Gazette No. 36 of 1998: 26 August 1998, No. 19182. Cape Town, RSA.

PEREIRA LS (1999) Higher performance through combined improvements in irrigation methods and scheduling: a discussion. Agric. Water Manage. 40 (2) 153-169.

PERRENS SJ (1984) Numerical analysis of soil water uniformity under sprinkler irrigation. J. Agric. Eng. Res. 30 23-27.

PITTS D, PETERSON K, GILBERT G and FASTENAU R (1996) Field assessment of irrigation system performance. Appl. Eng. Agric. 12 (3) 307-313.

ROGERS DH, LAMM FR, ALAM M, TROOIEN TP, CLARK GA, BARNES PL and MANKIN K (1997) Efficiencies and Water Losses of Irrigation Systems. [Internet]. Kansas State University, Research and Extension Engineers, Manhattan, USA. Available from: <http:// www.oznet.ksu.edu/library/ageng2/mf2243.pdf >. [Accessed 17 March 2000]

SABI (2000) Design Norms. [Internet]. South African Irrigation Institute (SABI), Strand, RSA. Available from: <http://www.sabi.co.za/html/ design_norms.html $>$. [Accessed 9 September 2000]

SOLOMON KH (1983) Irrigation Uniformity and Yield Theory. Ph.D. thesis, Utah State University, Utah State University, Logan, USA.

SOLOMON KH(1984) Yield related interpretations of irrigation uniformity and efficiency measures. Irrig. Sci. 5 161-172.

SOLOMON KH (1990) Sprinkler irrigation uniformity. [Internet]. Centre for Irrigation Technology, California State University, Fresno, USA. Available from: <http://www.wateright.org/site/publications/ 900803.html>. [Accessed 29 June 2000].

WRC (1999) Technical Report 1998- Water Research Commission. Water Research Commission, Pretoria, RSA.

ZOLDOSKE DF, SOLOMON KH and NORUM EM (1994) Uniformity measurements for turfgrass: what's best? [Internet]. Center for Irrigation Technology, California State University, Fresno, USA. Available from: <http://cati.csufresno.edu/cit/rese/94/941102.index.html〉. 
